\title{
Effect of methylprednisolone when added to standard treatment with intravenous immunoglobulin for Guillain-Barré syndrome: randomised trial
}

$R$ van Koningsveld, P I M Schmitz, F G A van der Meché, $L$ H Visser, J Meulstee, $P$ A van Doorn, for the Dutch GBS study group*

\begin{abstract}
Summary
Background Despite available treatment with intravenous immunoglobulin (IVIg), morbidity and mortality are considerable in patients with Guillain-Barré syndrome (GBS). Our aim was to assess whether methylprednisolone, when taken with IVlg, improves outcome when compared with IVIg alone.
\end{abstract}

Methods We did a double-blind, placebo-controlled, multicentre, randomised study, to which we enrolled patients who were unable to walk independently and who had been treated within 14 days after onset of weakness with IVIg $(0.4 \mathrm{~g} / \mathrm{kg}$ bodyweight per day) for 5 days. We assigned 233 individuals to receive either intravenous methylprednisolone (500 mg per day; $n=116$ ) or placebo $(n=117)$ for 5 days within $48 \mathrm{~h}$ of administration of first dose of IVlg. Because age is an important prognostic factor, we split treatment groups into two age-groups-ie, younger than age 50 years, or 50 years and older. Our primary outcome was an improvement from baseline in GBS disability score of one or more grades 4 weeks after randomisation. Analysis was by intention to treat.

Findings We analysed 225 patients. GBS disability scores increased by one grade or more in $68 \%$ (76 of 112) of patients in the methylprednisolone group and in 56\% (63 of 113) of controls (odds ratio [OR] 1.68, 95\% Cl 0.97-2.88; $\mathrm{p}=0.06$ ). After adjustment for age and degree of disability at entry, treatment OR was 1.89 (95\% Cl 1.07-3.35; $\mathrm{p}=0.03)$. Side-effects did not differ greatly between groups.

Interpretation We noted no significant difference between treatment with methylprednisolone and IVIg and IVIg alone. Because of the relevance of prognostic factors and the limited side-effects of methylprednisolone, the potential importance of combination treatment with the drug and IVIg, however, warrants further investigation.

Lancet 2004; 363: 192-96

See Commentary page 181

\section{Introduction}

Guillain-Barré syndrome (GBS) is an acute, immunemediated polyneuropathy. With an incidence of $1-1.5$ per 100000 people, it is the most common cause of acute flaccid paralysis in developed countries. ${ }^{1,2}$ Although most patients start to recover spontaneously within 2 weeks after the maximum weakness is reached, symptoms that range from fatigue to complete paralysis of the lower limbs often persist. ${ }^{3-5}$

Various treatments have been investigated based on the immune-mediated and inflammatory nature of the disease. The first randomised controlled trial ${ }^{6}$ of a treatment for GBS was published in 1978, and noted no significant benefit of monotherapy with low-dose, oral prednisolone, and the results of a study published in $1993^{7}$ showed no significant favourable effect at 4 weeks after randomisation of treatment with high-dose, intravenous methylprednisolone. Furthermore, the results of a Cochrane meta-analysis ${ }^{8}$ of six randomised trials indicated no beneficial effect of corticosteroids. The efficacy of plasma exchange was noted, however, in two large randomised controlled trials; ${ }^{9,10}$ in 1992 , the results of a Dutch trial ${ }^{11}$ showed that treatment with intravenous immunoglobulin (IVIg) was at least as effective as treatment with plasma exchange, a result confirmed in 1997 by the Plasma Exchange/ Sandoglobulin GBS Trial Group. ${ }^{12}$ Because treatment with IVIg is safer and more convenient than treatment with plasma exchange, IVIg became the treatment of choice for GBS. ${ }^{13,14}$

Despite these treatment options, however, the disease remains a serious one associated with great, longlasting morbidity. ${ }^{5,15,16}$ There is a need, therefore, to develop new treatments. A positive treatment effect with prednisone in chronic inflammatory demyelinating polyneuropathy, a closely related illness to GBS, has been established, ${ }^{17,18}$ and the results of a pilot study ${ }^{19}$ on the effect of high-dose intravenous methylprednisolone when given as an add-on therapy to standard treatment with IVIg indicate a beneficial effect of this combination of drugs in patients with GBS, as measured with the GBS disability score. We therefore decided to further assess whether combination treatment with methylprednisolone and IVIg improves outcome in patients with GBS to a greater extent than does IVIg alone.

\section{Methods \\ Patients}

Between July, 1994, and August, 2000, we assessed for eligibility in the study all patients admitted to 32 participating centres who fulfilled the National Institute of Neurological Disorders and Stroke criteria for GBS. $^{20}$ A patient was eligible for inclusion if their symptoms of weakness began within 2 weeks before the date of randomisation, if they were unable to walk $10 \mathrm{~m}$ across an open space without assistance (GBS disability score $\geqslant 3$ ), and if they were willing to sign the informed 
consent form. Exclusion criteria were age younger than 6 years, previous episodes of GBS, a previous severe allergic reaction to matched blood products, a known selective IgA deficiency, pregnancy, steroid treatment, contraindications for steroid treatment, severe concurrent disease, or foreseeable difficulties precluding follow-up.

Our protocol was approved by the ethics committee of every participating centre, and all patients provided written informed consent.

\section{Procedures}

Ours was a double-blind, placebo-controlled, multicentre, randomised study. All patients received IVIg (Gammagard SD, Baxter Bioscience, Brussels, Belgium) $0.4 \mathrm{~g} / \mathrm{kg}$ bodyweight per day for 5 consecutive days, starting immediately after enrolment. Patients were randomly assigned to also receive intravenous methylprednisolone $(500 \mathrm{mg}$ daily for adults and $8 \mathrm{mg} / \mathrm{kg}$ bodyweight for children, to a maximum of $500 \mathrm{mg}$ in $100 \mathrm{~mL}$ saline) or placebo (100 mL saline) for 5 days within $48 \mathrm{~h}$ of start of treatment with IVIg.

We stratified randomisation according to age $\quad<50$ or $\geqslant 50$ years) because of its effect on prognosis. ${ }^{10,11,21}$ We used block randomisation with random block sizes of 4,6 , or 8 generated by computer. When a neurologist identified a participant, they phoned a 24 -h hotline and were given a number, according to the randomisation list. The local hospital pharmacist subsequently prepared the trial medication (methylprednisolone or placebo), according to the randomisation number. In most cases neurologists responsible for patients' day-to-day care were not involved in assessment of treatment effect. We therefore assumed that unmasking was not an important issue in this trial.

Every week for the first 8 weeks after entry, every other week between weeks 9 and 14, every 4 weeks between weeks 15 and 26 , and once during week 52 or until the patient's GBS disability score fell to 1 or less, we assessed extent of cranial nerve dysfunction by neurological examination; GBS disability score $(0=$ healthy, $1=$ minor symptoms and capable of running, $2=$ able to walk $10 \mathrm{~m}$ or more without assistance but unable to run, $3=$ able to walk $10 \mathrm{~m}$ across an open space with help, $4=$ bedridden or chairbound, $5=$ needs assisted ventilation for at least part of the day, $6=$ dead); ${ }^{6}$ and Medical Research Council (MRC) sumscore. We assessed the MRC sumscore in six bilateral muscles of the arms and legs, yielding a sumscore that ranged from 60 (normal) to 0 (quadriplegic). ${ }^{22}$

Additional investigations included routine testing of blood, urine, and cerebrospinal fluid; electrophysiology; serological screening for previous infections with Campylobacter jejuni, cytomegalovirus, Epstein-Barr virus, and Mycoplasma pneumoniae; and stool cultures for previous infection with $C$ jejuni. With respect to electrophysiology, we assessed the compound muscle action potential (CMAP) of the ulnar nerve. IgM antibodies against cytomegalovirus were measured with ELISA. ${ }^{23}$ Results for MRC sumscores, cranial nerve dysfunction, sensory symptoms, blood, urine, and cerebrospinal fluid testing, detailed electrophysiology, and serological screening for infection will be reported in a separate paper.

We checked for expected adverse events daily and noted any changes in their severity every next visit. These included: respiratory tract infection, urinary tract infection, intravenous catheter sepsis, gastrointestinal bleeding, deep venous thrombosis, pulmonary embolism, serum glucose concentration greater than $10 \mathrm{mmol} / \mathrm{L}$, renal failure, and delirium. We asked participating neurologists to report any suspected major adverse events (not further defined) as soon as possible to the coordination centre at the Erasmus Medical Centre, Rotterdam, Netherlands.

Our primary endpoint was improvement from baseline by one or more grades on the GBS disability score 4 weeks after randomisation. Secondary endpoints were ability to walk independently after 8 weeks, time taken to improve by at least one grade on the GBS disability score, time taken to walk independently, difference in grade on the GBS disability score 6 months and 1 year after treatment, and difference in need for (at any time), and duration of, artificial respiration.

\section{Statistical analysis}

We compared the proportion of patients in the treatment and placebo groups whose GBS disability score decreased by one or more grades with the $\chi^{2}$ test (without correction for continuity); two-sided $p$ values are reported. We did Kaplan-Meier analyses and log-rank tests of time taken to reach an endpoint. We investigated prognostic factors that had had an effect on course of GBS in other studies, ${ }^{10,11,21}$-ie, age ( $<50$ years or $\geqslant 50$ years) and GBS disability score at baseline-by multivariate analysis. In a second multivariate analysis, we added three further factors of prognostic importance, which were significantly unbalanced between treatment groups: number of days between onset of weakness and randomisation ( $\leqslant 4$ days or $>4$ days), amplitude of CMAP ( $\leqslant 4 \mathrm{mV}$ or $>4 \mathrm{mV}$ ), and preceding infection with cytomegalovirus (yes or no). $C$ jejuni, generally accepted as an important prognostic factor, was not included because it was well balanced between the two treatment groups. In both multivariate models we also investigated the presence of interactions between the prognostic factors and treatment, to detect possible subgroups in which the effect of methylprednisolone might be stronger. For these multivariate

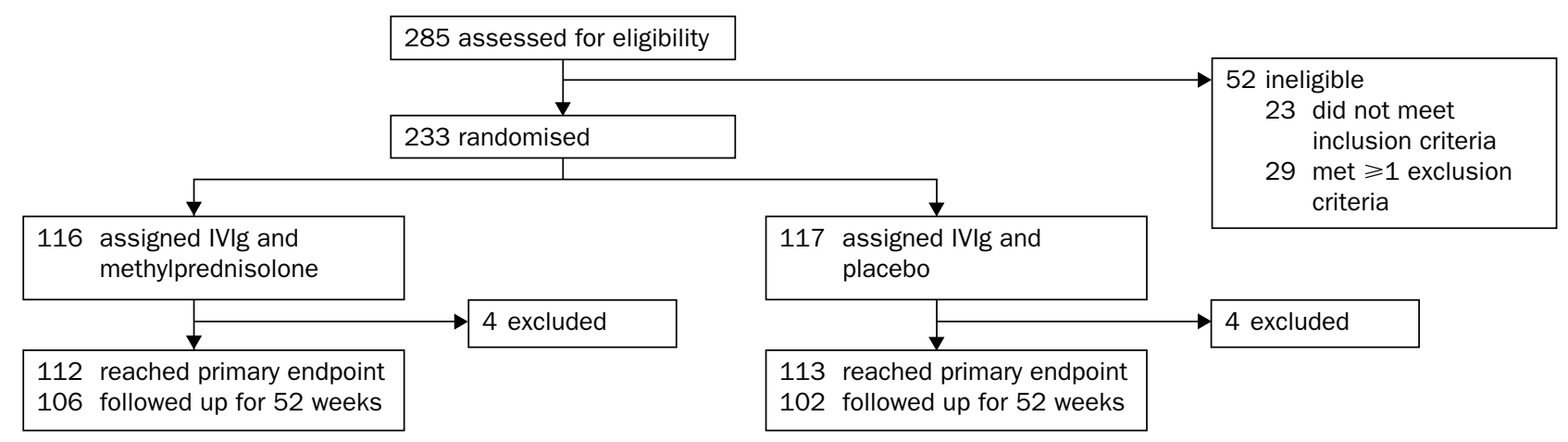

Figure 1: Trial profile 


\begin{tabular}{|c|c|c|}
\hline & $\begin{array}{l}\text { IVlg/ } \\
\text { methylprednisolone } \\
\text { group }(n=112)\end{array}$ & $\begin{array}{l}\text { IVIg/placebo } \\
\text { group }(n=113)\end{array}$ \\
\hline \multicolumn{3}{|l|}{ Characteristics } \\
\hline \multicolumn{3}{|l|}{ Sex } \\
\hline Male & $73(65 \%)$ & $57(50 \%)$ \\
\hline Female & $39(35 \%)$ & $56(50 \%)$ \\
\hline \multicolumn{3}{|l|}{ Age (years) } \\
\hline Median (90\% intercentile range) & $58(11-81)$ & $52(12-77)$ \\
\hline$<50$ & 44 (39\%) & 48 (42\%) \\
\hline$\geqslant 50$ & $68(61 \%)$ & $65(58 \%)$ \\
\hline \multicolumn{3}{|l|}{ Disability score at baseline } \\
\hline 3 & $26(23 \%)$ & $32(28 \%)$ \\
\hline 4 & 77 (69\%) & $80(71 \%)$ \\
\hline 5 & $9(8 \%)$ & $1(1 \%)$ \\
\hline $\begin{array}{l}\text { Median ( } 90 \% \text { intercentile range) } \\
\text { number of days of muscle weakness } \\
\text { before randomisation }\end{array}$ & $4(1-14)$ & $6(2-13)$ \\
\hline Diarrhoea & $30(27 \%)$ & $30(26 \%)$ \\
\hline Positive cytomegalovirus serology & $16(15 \%)$ & $12(12 \%)$ \\
\hline Positive $C$ jejuni serology & $29(28 \%)$ & $28(29 \%)$ \\
\hline CMAP $>4 \mathrm{mV}$ & $25(27 \%)$ & $11(13 \%)$ \\
\hline
\end{tabular}

Data are number (\%) unless otherwise indicated.

Table 1: Baseline characteristics

analyses of the dichotomous primary endpoint, logistic regression was used to obtain all odds ratios (ORs; unadjusted and adjusted) and their $95 \%$ CIs. p values in these models are based on Wald's test. All analyses were by intention to treat, and were done with STATA (version 6). We also undertook a per-protocol univariate analysis. On the basis of the results of the first trial with $\operatorname{IVIg}^{11}$ and those of the pilot study ${ }^{19}$ on the additional effect of methylprednisolone when given in combination with IVIg, we estimated that the chance of a patient's GBS disability score improving by one or more grades 4 weeks after randomisation was $50 \%$ in the placebo group and $70 \%$ in the methylprednisolone group.

Our interim analysis was based on a sequential group design described by Geller and Pocock. ${ }^{24}$ Two interim analyses were planned-the first, in 75 patients, to be stopped when the $\mathrm{p}$ value of the difference in primary outcome between the placebo and treatment groups reached a threshold of 0.014 , and the second, in 150 patients, when the $\mathrm{p}$ value of the difference between the two groups reached a threshold of $0 \cdot 021$. We judged a $p$ value of less than 0.03 significant for the final analysis. To obtain a nominal $\alpha$ of 0.05 we had to increase the sample size from 182 to 228 patients with the $\beta$ error set at $0 \cdot 2$.

\section{Role of the funding source}

The financial support of Baxter Bioscience consisted of cofinancing a datamanager and meetings of the investigators. The sponsors had no role in study design, data collection, data analysis, data interpretation, writing of the report, or in the decision to submit the paper for publication

\section{Results}

Figure 1 shows the trial profile and table 1 the baseline characteristics of patients. The most frequently reported exclusion criterion was treatment with immunosuppressive drugs within 1 month before randomisation. Eight patients, four in each group, were excluded from analyses for the following reasons: one patient had a GBS disability score of 2 at time of randomisation (eligibility criteria score $\geqslant 3$; the participating neurologist stopped scoring the patient after noticing this mistake 13 days after randomisation); the diagnosis of one patient was unclear and they were lost to follow-up soon after randomisation; one patient was aged 9 years and after randomisation the medical ethics committee of the hospital noted it had not given permission to randomise patients younger than 18 years; by mistake, one patient did not receive any trial drug (the participating neurologist noticed this error a few days after randomisation and stopped scoring the patient); one patient was randomised before ethics committee approval had been received at the centre (the neurologist stopped scoring); and three patients were diagnosed with cauda equina syndrome, Miller Fisher syndrome, and cervical stenosis rather than GBS between randomisation and the fourth week of the trial (time of primary endpoint; participating neurologists stopped scoring the patients after their diagnosis was altered).

With respect to the primary endpoint, results of neither interim analysis showed a significant difference between the two treatment groups. In the final intention-to-treat analysis, we noted an improvement of one or more grades on the GBS disability score in 63 of $113(56 \%)$ controls and 76 of $112(68 \%)$ patients in the methylprednisolone group (OR $1 \cdot 68,95 \%$ CI $0 \cdot 97-2 \cdot 88 ; p=0 \cdot 06$ ). In the perprotocol analysis, from which 20 patients were excluded mostly because of minor treatment violations, we noted an improvement of one or more grades on the GBS disability score in $56 \%$ (58 of 104) of patients in the placebo group and $70 \%(71$ of 101$)$ in the treatment group $(1.88$, $1 \cdot 05-3 \cdot 34 ; \mathrm{p}=0 \cdot 03)$.

Table 2 shows the results of the seven secondary outcome measures, none of which differed significantly between groups. Figure 2 shows the proportion of patients who recovered to independent locomotion (GBS disability score 2) during the 52 weeks of follow-up $(p=0.37)$, and figure 3 shows the proportion of patients that improved by one or more grades during this time $(\mathrm{p}=0 \cdot 15)$.

For effect of prognostic factors, the multivariate analysis of treatment (methylprednisolone vs placebo), age $(<50$ years $v s \geqslant 50$ years), and GBS disability score at entry resulted in an unadjusted treatment $O R$ of $1.89(95 \%$ CI $1.07-3.35 ; p=0.03)$ and an OR adjusted for age and GBS score of $1.73(0.96-3 \cdot 10 ; p=0.07)$ and $0 \cdot 28(0 \cdot 13-0 \cdot 58 ; \mathrm{p}=0 \cdot 001)$, respectively. The extended multivariate analysis, including these factors and number of days between onset of weakness and randomisation ( $\leqslant 4$ days or $>4$ days), amplitude of CMAP ( $\leqslant 4 \mathrm{mV}$ or $>4 \mathrm{mV}$ ), and preceding infection with cytomegalovirus (yes or no), resulted in a treatment OR of 2.96 $(1 \cdot 26-6 \cdot 94 ; \mathrm{p}=0.01)$ and the following adjusted ORs: age $2 \cdot 41(1.01-5 \cdot 76 ; p=0 \cdot 05)$, GBS score $0.40(0 \cdot 15-1 \cdot 06$; $\mathrm{p}=0 \cdot 06)$, duration of weakness $2 \cdot 80(1 \cdot 21-6 \cdot 48 ; \mathrm{p}=0 \cdot 02)$,

\begin{tabular}{|c|c|c|c|}
\hline & $\begin{array}{l}\text { IVIg/ } \\
\text { methylprednisolone } \\
\text { group }(n=112)\end{array}$ & $\begin{array}{l}\text { IVlg/placebo } \\
\text { group } \\
(n=113)\end{array}$ & $\mathbf{p}$ \\
\hline \multicolumn{4}{|l|}{ Endpoint } \\
\hline $\begin{array}{l}\text { Ability to walk independently } \\
\text { after } 8 \text { weeks (number, \%) }\end{array}$ & $78(70 \%)$ & $68(60 \%)$ & $0 \cdot 14$ \\
\hline $\begin{array}{l}\text { Median (IQR) number of days } \\
\text { taken to walk independently } \\
\text { (GBS disability score } 2 \text { ) }\end{array}$ & $28(14-154)$ & $56(14-154)$ & 0.37 \\
\hline $\begin{array}{l}\text { Median (IQR) number of days } \\
\text { taken to reach GBS disability } \\
\text { score of } 1\end{array}$ & $21(7-42)$ & 21 (14-98) & $0 \cdot 15$ \\
\hline $\begin{array}{l}\text { Median }(95 \% \mathrm{Cl}) \text { GBS disability } \\
\text { score at } 6 \text { months }\end{array}$ & $3(2-3)$ & $3(2-3)$ & 0.41 \\
\hline $\begin{array}{l}\text { Median }(95 \% \mathrm{CI}) \text { GBS disability } \\
\text { score at } 1 \text { year }\end{array}$ & $3(3-3)$ & $3(3-3)$ & 0.37 \\
\hline $\begin{array}{l}\text { Need for artificial respiration } \\
\text { (number, \%) }\end{array}$ & 24 (21\%) & $26(23 \%)$ & 0.77 \\
\hline $\begin{array}{l}\text { Median }(95 \% \mathrm{Cl}) \text { number of } \\
\text { days of artificial respiration }\end{array}$ & $30(16-52)$ & $26(13-43)$ & 0.51 \\
\hline
\end{tabular}

Table 2: Secondary endpoints 


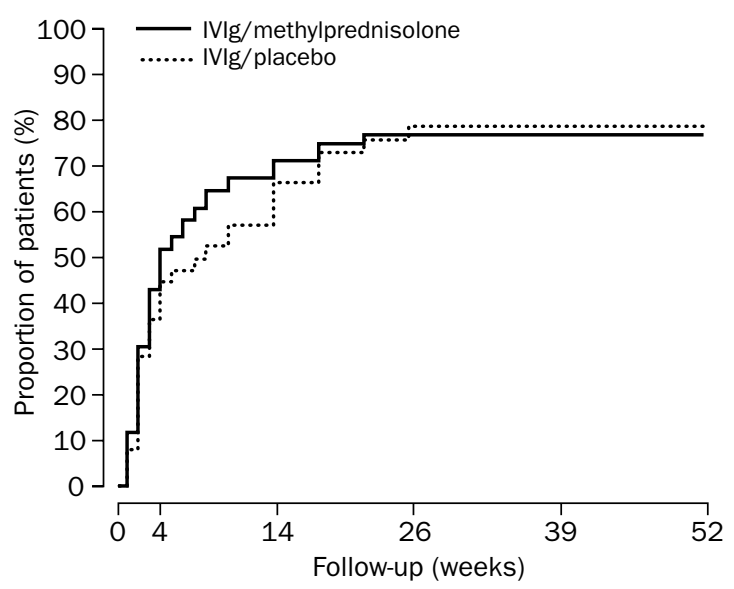

Numbers at risk

$\begin{array}{llllll}\begin{array}{l}\text { IVIg/methyl- } \\ \text { prednisolone }\end{array} & 11264 & 35 & 24 & 24 & 22\end{array}$

$\begin{array}{llllll}\text { IVIg/placebo } & 11372 & 46 & 26 & 26 & 19\end{array}$

Figure 2: Kaplan-Meier curves of proportion of patients able to walk independently after 52 weeks' follow-up

CMAP $0.25(0 \cdot 10-0 \cdot 64 ; \mathrm{p}=0 \cdot 004)$, and cytomegalovirus infection $0.23(0.08-0 \cdot 69 ; \mathrm{p}=0.009)$. We did not note any significant treatment interactions in either multivariate analysis and, therefore, no subgroups were detected in which the effect of methylprednisolone was better than placebo.

With respect to adverse events, four patients in the placebo group and six in the methylprednisolone group died. Among those on placebo, one died on the second day after randomisation because of a subarachnoid haemorrhage, one died 22 weeks after randomisation from intracerebral bleeding and pancytopenia, one had severe autonomic dysfunction that resulted in hypoxic ischaemic encephalopathy and multiorgan failure (artificial respiration was stopped 4 weeks after randomisation), and a fourth patient died 5 months after randomisation because of a cerebrovascular accident after an operation on a damaged aortic valve. Of those taking methylprednisolone, one died from a cardiac arrest on the second day after randomisation, one died 4 weeks after randomisation from hypovolaemic shock after gastrointestinal bleeding, one was

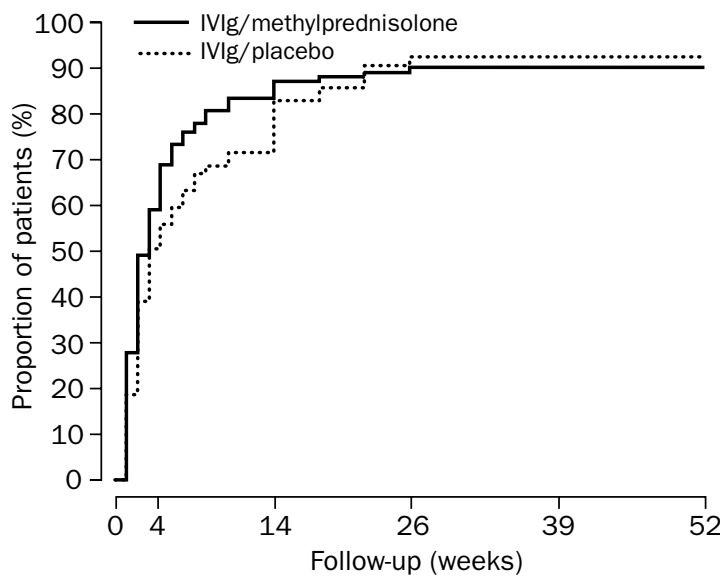

Numbers at risk

$\begin{array}{llllll}\begin{array}{l}\text { IVIg/methyl- } \\ \text { prednisolone }\end{array} & 11246 & 18 & 11 & 11 & 10\end{array}$

prednisc

IVlg/placebo 11356

30

10

10

7

Figure 3: Kaplan-Meier curves of proportion of patients whose GBS disability score improved by 1 or more during 52 weeks' follow-up found dead 9 weeks after randomisation and is thought to have died from a cardiac arrest. A fourth patient, recovering from his paresis, died of unknown causes 3 months after randomisation; there were no signs of cardiac or pulmonary insufficiency. A fifth patient died 7 months after randomisation. He was 84 years old and had increasing cardiac and pulmonary insufficiency with massive water retention. The cause of death was probably a cardiac arrest. The sixth patient died 5 months after randomisation from sepsis. He had been on a ventilator for 3 months and developed high fever and sepsis after 4 months. Antibiotics and oxygen were given, but he died in bed 1 week later.

$34(30 \%)$ controls and $18(16 \%)$ individuals on methylprednisolone developed urinary-tract infections $(p=0.02)$. We noted a temporary rise in serum glucose concentrations to about $10 \mathrm{mmol} / \mathrm{L}$ in more patients in the methylprednisolone group than in controls (23 of 109 , $21 \%$, vs seven of $110,6 \%, p=0 \cdot 002)$, whereas hypertension was more frequently reported in controls (12 of 96, $13 \%$, vs two of $105,2 \%, p=0 \cdot 001)$.

\section{Discussion}

Our results indicate no significant effect of methylprednisolone when given with IVIg to patients with GBS, unless various factors known to affect the prognosis of disease, and which seemed unbalanced between groups at baseline, are adjusted for.

The secondary outcome measurements, mainly concerning long-term effects, did not differ significantly between the two groups. In the North American trial, ${ }^{9}$ the median time taken for an untreated patient to recover sufficiently to walk independently was 85 days. This time was reduced to 51 days and 55 days after treatment with IVIg in the Dutch GBS trial ${ }^{11}$ and the Sandoglobulin GBS trial, ${ }^{12}$ respectively, and, in our study, patients treated with IVIg and methylprednisolone were walking independently in a median time of 28 days.

The mortality rate in our trial was $4 \%$; slightly less than previously reported. ${ }^{2,415}$ More patients died in the methylprednisolone group than in the placebo group. However, since four of the six patients died more than 8 weeks after randomisation, it is unlikely that their deaths were related to the drug under investigation. Furthermore, the patient who died on the second day after randomisation from a cardiac arrest fell ill during an IVIg infusion; no methylprednisolone had yet been administered. In one patient, however, who died 4 weeks after randomisation from gastrointestinal bleeding, no cause for the bleeding could be established; methylprednisolone cannot, therefore, be excluded as the cause. Of the minor complications, a transient rise in serum glucose was more frequently reported in the treatment group than in controls. Also, in accord with the results of a trial done by the GBS Steroid Trial Group, ${ }^{7}$ we noted fewer instances of hypertension in the methylprednisolone group than in the placebo group. Since the GBS Steroid Trial Group has suggested a protective role of methylprednisolone on renal function, we are now undertaking an analysis of renal function in our participants.

The mechanism by which IVIg works in GBS is unclear. The results of two early trials ${ }^{6,7}$ showed no benefit of treatment with low-dose steroids or high-dose prednisolone treatment. Furthermore, if and how steroids act on the pathophysiological mechanism of GBS is unknown. One theory is that they could inhibit inflammation, leading to a decrease of endoneurial pressure and oedema, which cause ischaemia in nerve trunks. ${ }^{25-27}$ 
Although our findings did not indicate a significant difference in treatment effect between patients given methylprednisolone and IVIg and those given IVIg alone, we believe the two drugs might work synergistically. Furthermore, because of the relevance of prognostic factors and the limited side-effects of the drugs, we believe the combination warrants further investigation.

Contributors

$\mathrm{R}$ van Koningsveld was study coordinator, collected data, analysed results, and wrote and edited the report; P I M Schmitz designed the study, analysed results, and helped write the manuscript; F G A van der Meché helped design the study and write the report; L H Visser and J Meulstee were involved in study design and collection of data; P A van Doorn helped design the study, collect the data, and write and edit the report.

\section{Members of Dutch GBS study group who participated in study} (number of patients randomised)

Netherlands-J A van Leusden and M M Veering, Medisch Centrum Alkmaar, Alkmaar (12); R Bijlsma and A Hovestadt, Eemland Ziekenhuis, Amersfoort (1); I van Schaik, Academisch Medisch Centrum, Amsterdam (5); W H J P Linssen, Sint Lucas Andreas Ziekenhuis, Amsterdam (7); R A J A M Bernsen, Bosch Medicentrum, Den Bosch (5); J T J Tans and A W de Weerd, Medisch Centrum Haaglanden, Den Haag (4); D L J Tavy, Ziekenhuis Leijenburg, Den Haag (5); W J Feikema, Deventer Ziekenhuizen, Deventer (2); R P Kleijweg, Albert Schweitzer Ziekenhuis, Dordrecht (5); A Vermeij, J de Jonge, and K Keizer, Diaconessen/Catharina Ziekenhuis, Eindhoven (9); J A G Geelen and G Wilts, Medisch spectrum Twente, Enschede (6); Th J M Breuer, St Annaziekenhuis, Geldrop (1); F Visscher and A M Boon, Stichting Oosterscheldeziekenhuizen, Goes (5); A E J de Jager and T W van Weerden, Academisch Ziekenhuis Groningen, Groningen (14); P J J Koehler and J W Vredeveld, Atrium Medisch Centrum, Heerlen (10); J C Koetsveld, Baart, St Streekziekenhuis Midden Twente, Hengelo (2); J J G M Verschuuren and A R Wintzen, Leids Universitair Medisch Centrum, Leiden (4); E de Vries, Leenders, I Jsselmeer Ziekenhuizen, Lelystad (2); H Kerkhoff and M de Baets, Academisch Ziekenhuis Maastricht, Maastricht (4); B G M van Engelen and G W Padberg, Universitair Medisch Centrum St Radboud, Nijmegen (7); W I M Verhagen and C W G M Frenken, J Meulstee, Canisius Wilhelmina Hospital, Nijmegen (6); R van Koningsveld, P A van Doorn, Erasmus MC, Rotterdam (42); H A W Sinnege, Medisch Centrum Rijnmond-Zuid, Rotterdam (5); H W M Anten, Maasland Ziekenhuis, Sittard (1); R L A A Schellens, L H Visser, Sint Elisabeth Ziekenhuis, Tilburg (14); $\mathrm{L} H$ van den Berg and $\mathrm{H}$ Franssen, Universitair Medisch Centrum Utrecht, Utrecht (17); B J van Kasteren and J A P Hiel, Sint Joseph Ziekenhuis, Veldhoven (9).

Belgium-M Van Zandijcke and V Schotte Sint Jan, AV, Brugge (6); P Y K Van den Bergh and C J M Sindic, Clinique Universitaire St Luc, Brussel (10).

Germany-L Harms, Medizinische Fakultät Charité, Berlin (13); W Hacke and E Hund, Ruprecht-Karls Universität, Heidelberg (9).

Conflict of interest statement

None declared.

\section{Acknowledgments}

We thank Monica van der Hoven, who sadly died during preparation of the report, for her dedicated support and excellent data management, Martin Lee for his critical remarks and valuable suggestions with respect to statistical analysis, and P Herbrink and C W Ang for undertaking campylobacter serology. Baxter Bioscience, Brussels, Belgium, provided financial support.

\section{References}

1 Rees JH, Thompson RD, Smeeton NC, Hughes RAC Epidemiological study of Guillain-Barre syndrome in south east England. F Neurol Neurosurg Psychiatry 1998; 64: 74-77.

2 van Koningsveld R, Van Doorn PA, Schmitz PIM, Ang CW, van der Meché FGA. Mild forms of Guillain-Barré syndrome in an epidemiologic survey the Netherlands. Neurology 2000; 54: 620-25.

3 Merkies IS, Schmitz PI, Samijn JP, van der Meché FG, van Doorn PA. Fatigue in immune-mediated polyneuropathies. Neurology 1999; 53: 1648-54.
4 de Jager AEJ, Minderhoud JM. Residual signs in severe GuillainBarré syndrome: analysis of 57 patients. F Neurol Sci 1991; 104: 151-56.

5 Fletcher DD, Lawn ND, Wolter TD, Wijdicks EF. Long-term outcome in patients with Guillain-Barre syndrome requiring mechanical ventilation. Neurology 2000; 54: 2311-15.

6 Hughes RA, Newsom-Davis JM, Perkin GD, Pierce JM. Controlled trial of prednisolone in acute polyneuropathy. Lancet 1978 ; 2: $750-53$.

7 Guillain-Barré Syndrome Steroid Trial Group. Double-blind trial of intravenous methylprednisolone in Guillain-Barré syndrome. Lancet 1993; 341: 586-90.

8 Hughes RAC, van der Meché FGA. Corticosteroids for Guillain-Barré syndrome (Cochrane Review). In: The Cochrane Library, issue 3. Oxford: Update Software, 2003.

9 The Guillain-Barré study group. Plasmapheresis and acute GuillainBarré syndrome. Neurology 1985; 35: 1096-104.

10 French Cooperative Group on plasma exchange in Guillain-Barré syndrome. Efficiency of plasma exchange in Guillain-Barré syndrome: role of replacement fluids. Ann Neurol 1987; 22: 753-61.

11 van der Meché FGA, Schmitz PIM, Dutch Guillain-Barré Study Group. A randomized trial comparing intravenous immune globulin and plasma exchange in Guillain-Barré syndrome. N Engl f Med 1992; 326: 1123-29.

12 Plasma Exchange/Sandoglobulin Guillain-Barré Syndrome Trial Group. Randomised trial of plasma exchange, intravenous immunoglobulin, and combined treatments in Guillain-Barré syndrome. Lancet 1997; 349: 225-30.

13 Hahn AF. Guillain-Barré syndrome. Lancet 1998; 352: 635-41.

14 Hughes RA, Raphael JC, Swan AV, van Doorn PA. Intravenous immunoglobulin for Guillain-Barré syndrome (Cochrane Review). In: The Cochrane Library, issue 3. Oxford: Update Software, 2003.

15 Hadden RDM, Karch H, Hartung HP, et al. Preceding infections, immune factors, and outcome in Guillain-Barré syndrome. Neurology 2001; 56: 758-65.

16 Ropper AH, Wijdicks EFM, Truax BT. Guillain-Barré syndrome. Philadelphia: FA Davis Company, 1991.

17 Dyck PJ, O'Brien PC, Oviatt KF, et al. Prednisone improves chronic inflammatory demyelinating polyradiculoneuropathy more than no treatment. Ann Neurol 1982; 11: 136-41.

18 Hughes R, Bensa S, Willison H, et al. Randomized controlled trial of intravenous immunoglobulin versus oral prednisolone in chronic inflammatory demyelinating polyradiculoneuropathy. Ann Neurol 2001; 50: 195-201.

19 The Dutch Guillain-Barré Study Group. Treatment of Guillain-Barré syndrome with high-dose immune globulins combined with methylprednisolone: a pilot study. Ann Neurol 1994; 35: 749-52.

20 Asbury AK, Cornblath DR. Assessment of current diagnostic criteria for Guillain-Barré syndrome. Ann Neurol 1990; 27 (suppl): S21-24.

21 McKhann GM, Griffin JW, Cornblath DR, Mellits ED, Fisher RS, Quaskey SA. Plasmapheresis and Guillain-Barré syndrome: analysis of prognostic factors and the effect of plasmapheresis. Ann Neurol 1988; 23: 347-53.

22 Anon. Aids to the investigation of the peripheral nervous system. London: HMSO, 1976.

23 Visser LH, van der Meché FGA, Meulstee J, et al. Cytomegalovirus infections and the Guillain-Barré syndrome, the clinical, electrophysiological and prognostic features. Neurology 1996; 47: 668-73.

24 Geller NL, Pocock SJ. Interim analysis in randomised clinical trials: ramifications and guidelines for practitioners. Biometrics 1987; 43: 213-23.

25 Kazatchkine MD, Kaveri SV. Immunomodulation of autoimmune and inflammatory diseases with intravenous immune globulin. N Engl f Med 2001; 345: 747-55.

26 Berciano J, Figols J, García A, et al. Fulminant Guillain-Barré syndrome with universal inexcitability of peripheral nerves: a clinicopathological study. Muscle Nerve 1997; 20: 846-57.

27 Berciano J. Rational therapy of Guillain-Barré syndrome. Lancet 1998; 351: 754-55. 